\title{
Indigenous Technologies and Innovation in Nigeria: Opportunities for SMEs ${ }^{*}$
}

\author{
Willie O. Siyanbola, Abiodun A. Egbetokun, Isola Oluseyi, Olumuyiwa O. Olamade, \\ Helen O. Aderemi ${ }^{\#}$, Mohammed Sanni
}

National Centre for Technology Management, Obafemi Awolowo University, Ile-Ife, Nigeria.

Email: \#aderemi.helen@gmail.org

Received December $28^{\text {th }}, 2011$; revised February $6^{\text {th }}$, 2012; accepted February $17^{\text {th }}, 2012$

\begin{abstract}
The aim of this paper is to advance the position that Nigeria's indigenous technologies present significant opportunities for local economic transformation and, to some extent, for global competitiveness. An analysis of three major indigenous technology clusters in Nigeria, as well as a review of three successful country cases was performed. This was with a view to identifying structural and policy directions for the country. The study provided preliminary insight into a very broad landscape and call for further analyses relating to mapping the Indigenous Knowledge (IK) and Indigenous Technology (I-Tech) systems of economies.
\end{abstract}

Keywords: Indigenous; Technologies; Innovation; Clusters; Economic; Competitiveness

\section{Introduction}

In today's globalised world, economic activities have shifted from largely domestic affairs to more complex international relationships; and that, in itself, poses new challenges. For instance, due to the abundance of knowledge, the unprecedented cross-border transferability of information and the removal of trade barriers, the occurrence of externalities within nations has significantly increased [1]. Consequently, one of the most significant challenges that developing economies have to face relates to the attainment of competitive advantages in key economic sectors. As the UN Millennium Project [2] noted, despite the increasing globalization of technology, the involvement of developing countries in producing new technologies and innovations is almost negligible. The production of technological knowledge is concentrated in industrial countries and developing nations are still lagging behind as far as competition on the technological frontiers is concerned.

Given the foregoing, it stands to reason that poor de-

\footnotetext{
*This chapter uses results from two policy research projects of the National Centre for Technology Management (NACETEM). The projects Indigenous Technology Mapping and Analysis of Skills Acquisition Methodologies in the Aluminium and Bronze Casting Industry in Nigeria and Indigenous Technology Mapping and Analysis of Skills Acquisition Methodologies in Nigeria: Leather Tanning were funded in 2006 and 2007 respectively by the Federal Government of Nigeria through the Federal Ministry of Science and Technology (FMST). For enquiries, e-mail: dg.ceo@nacetem.org or call +234(0)8033449687.

"Corresponding author.
}

veloping economies may be better positioned in the game of global competition if, rather than exclusively focusing on catching-up at the frontiers, they look inwards to deploy science, technology and innovation (STI) in specific areas where they have comparative advantage. These comparative advantages could then be developed to achieve competitive advantage ${ }^{1}$. The cases with Salmon fishery in Chile, as well as herbal medicine in China and India [3] are useful cases of indigenous technologies that have been exploited. Also, the kiondo basket though weaved and used in Kikuyu and Kamba communities in Kenya was exploited and protected under Japanese patent with the Kenya communities receiving none of the financial rewards [4].

In this paper, we examine three major indigenous technology clusters in Nigeria and three successful country cases. The intent of this is to identify structural and policy directions for the country as well as provide preliminary insight for further mapping of IK and I-Tech systems of economies. It is worthy of note that Nigeria's indigenous technologies also present significant opportunities for local economic transformation and, to some extent, for global competitiveness. This would happen when these technologies are improved and standardized through the deployment of science and technology. With a focus on cottage, small and medium-sized enterprises, businesses could be developed around these technologies which would foster national innovativeness, create em-

\footnotetext{
See [5-7] for an expansion of this argument.
} 
ployment and generate wealth.

The rest of the paper is structured as follows. In Section 2 we examine the concepts of indigenous technologies, innovation and SMEs as well as their complementtarities. This is followed with a brief examination of some country cases where indigenous technologies have been deployed towards national competitiveness. The methodology adopted for the survey comes next after the country cases. The results which highlighted some of Nigeria's indigenous technologies having comparative competitive potentials are discussed in Section 5. This result is based on two years of analyses that has been carried out at the National Centre for Technology Management (NACETEM). Section 6 highlights the opportunities in these technologies for entrepreneurship and SME development, raising some policy issues. Some concluding remarks are offered in Section 7.

\section{Indigenous Knowledge, Indigenous Technologies, Innovation and Small and Medium-Sized Enterprises}

As with several key concepts like science and technology, innovation and entrepreneurship, there seems to be no single universal definition of indigenous knowledge (IK) ${ }^{2}$ but the fundamentals are clear. Contrasting IK with globalised knowledge, Warren et al. [8] noted that it is the local knowledge that is unique to a given culture or society. Focusing on the sources of IK, it was defined [9] as the unique, traditional, local knowledge existing within and developed around specific conditions of women and men indigenous to a particular geographic area. A particular commonality to be noted is that IK generally refers to the matured long-standing traditions and practices of certain regional, indigenous, or local communities as well as the wisdom, knowledge, and teachings of these communities. Thus, whichever way it is defined, four things characterise IK:

1) It is centred on local or indigenous peoples and their beliefs or practices;

2) It is generally bound by geography in that the knowledge, most often, does not transcend the locality where it originates;

3) It is generally tacit in nature, being most times orally passed from person to person, for generations;

4) It is not dated in the sense that the knowledge or practices do not necessarily have to be primordial.

At its most basic level, technology is defined as the application of knowledge to provide solutions to problems, mostly of mankind. Some forms of traditional knowledge are expressed through stories, legends, folklore, rituals, songs, and even laws while other forms are

${ }^{2}$ The terms traditional and local are sometimes used in place of indigenous. often expressed through different means [3]. When IK finds applications in tools, techniques, processes and methods that help in solving problems, indigenous technologies $\left(\mathrm{I}-\mathrm{Tech}^{3}\right)$ arise. Notable examples include the making of talking drums in Oyo (South-Western Nigeria), the fabrication of aluminium pottery in Saki (SouthWestern Nigeria), the production of beads in Bida (North-Central Nigeria), leather works in Zaria (NorthCentral Nigeria) and the production/beauty applications of special skin-friendly dyes called lalli in Northern Nigeria. In many cases, certain families are known for certain I-Techs. For instance, talking drum fabrication is traditionally associated with certain ile onilu families in Oyo. Outside Nigeria, one can talk of the mummification techniques for preserving the remains of dead Pharaohs in Egypt - the knowledge of which was restricted to the Egyptian palaces and the scientific basis of which till today remains incompletely resolved [10]. Such is the power of IK and I-Tech!

In this new economic order, developing nations can no longer compete based only on their natural resource endowments and location advantages. For a nation to withstand competition in this era of globalization there is need for such to identify its niche areas and build on it by the application of scientific methods. New technologies and industries may then be built around these areas of core competences. Indeed, the wealth of indigenous knowledge and technologies in Nigeria presents unique and inimitable opportunities for innovation to occur and significant avenues for growth. What has been achieved in China and India with herbal medicine [3] is a useful case in point.

Innovation is regarded as the use of new knowledge to offer a new product or service that consumers want [11]. Oyeyinka-Oyelaran [12] stressed the fact that the application of that knowledge is to be emphasised rather than its acquisition. In less developed countries, Lall [13] has suggested that innovation must be thought of as a process of adoption, absorption and diffusion of available technology. When talking of innovation in a less developed economy like Nigeria, UNCTAD [14] noted that it matters much more for countries to focus on the adaptation, diffusion and upgrading of technologies that already exist rather than pushing (or even attempting to push) the global knowledge frontier further. It follows, then, that I-Techs offer significant opportunities for innovation in Nigeria. This is so for two main reasons: they are already available and they are already acceptable.

As earlier noted, most IK and I-Tech are tacit in nature and are transferred in unwritten manners. To exploit them formally for innovation presents challenges, therefore.

\footnotetext{
${ }^{3}$ The contraction $I T$, though readily obvious, cannot be used here lest there be a confusion of indigenous technologies with information technology.
} 
For instance, there is the problem of standardisation that has always been an issue with local technologies and practices such as blacksmithing and traditional medicine $[15,16]$. There is also the issue of codification which makes knowledge transfer easier and preserves its integrity over time. Nonetheless, small and medium-sized enterprises (SMEs) are well-positioned to overcome these challenges. Given the nature of IK and I-Techs, most practitioners involved in them are usually dependent on family and apprentices for manpower. The stage thus seems to be set for SME development. If standardisation is achieved, enterprises that are more organised could evolve around these technologies.

The focus on SMEs as major players in the exploitation of IK and I-Techs for national competitiveness is premised upon sound reason. SMEs are highly instrumental in the economic growth of any nation for several reasons. First, they provide a more efficient medium than Large Scale Enterprises (LSEs) for the training of unskilled and semi-skilled labour, and are suitable for mobilizing small credits for productive purposes [17]. This is possibly due to their operational flexibility, ability to form cooperatives and cartels. In addition, SMEs create more jobs than large businesses because more of them are started in any given period than are large businesses. The sizes of these SMEs ${ }^{4}$ enable greater flexibility in management and offer viable testing ground for new technologies. They also promote industrial and economic development through the utilization of local resources, production of intermediate goods and the transfer/transformation of rural technology [19]. Indeed, SMEs present the best opportunity for rural development.

In Nigeria, SMEs are already found in a wide array of business activities. These range from the single artisan producing agricultural implements for the village market, the coffee shop at the corner, the internet café in a small town to a small sophisticated engineering or software firm selling in overseas markets and a medium-sized automotive parts manufacturer selling to multinational automakers in the domestic and foreign markets. The owners may or may not be poor; the firms operate in very different markets (urban, rural, local, national, regional and international); embody different levels of skills, capital, sophistication and growth orientation, and may be in the formal or the informal economy. Together, these firms account for about $90 \%$ of all industrial enter-prises, $10 \%$ of total manufacturing output and $70 \%$ of industrial employment in Nigeria $[18,20]$. In addition, SME contributes about 30\% of Gross Domestic Product (GDP) and accounts for about $58 \%$ of global working population

\footnotetext{
${ }^{4}$ Ramachandran [18] argued that SMEs in the Nigerian context are best defined as those with fewer than 100 employees and below 50 million naira in assets. The lower limit for this characterisation (in terms of employment) beyond which a firm is regarded as a micro enterprise is 10 employees [19].
}

[21]. Their contributions to national economy are in terms of output of goods and services and adapting appropriate technologically approaches among others [22]. Given the foregoing, some of the major steps that remain to be taken are to put in place appropriate mecha- nisms for the upgrading of existing micro outfits in IK and I-Tech, create structures that favour business development in the IK and I-Tech sectors, and facilitate the deployment of knowledge from knowledge centres in these sectors.

\section{Innovation in the Indigenous Technology Sector: Selected Country Cases}

For a nation to withstand competition in this era of globalisation, there is need for such to identify its niche areas and build on it by the application of scientific methods. It has been argued that indigenous knowledge and technologies present excellent possibilities in this regard. In this section, we discuss how two selected countries (China and India) have excelled in the exploitation of indigenous technologies. The focus is on traditional medical knowledge in China and on the creation of strong institutions in the I-Tech sector in India.

\subsection{Traditional Medicine in China}

Historically, the Chinese believe a lot in nature and they reverence it. They make use of natural products which pioneered indigenous medicine. For instance, rather than offering synthesized drinks and beverages or expensive wine to visitors, the Chinese historically held tea ceremonies in which they use fresh or dried tea leaves to prepare natural tea. This tradition has stayed with them till today [3]. Perhaps consequent upon that, they are generally very healthy and have a longer life span (average life expectancy of 73 years for 2005-2010 compared. to about 47 years in Nigeria ${ }^{5}$ ). Chinese are mostly smart, active and light-weighed probably because the intake of natural herbs has become an household practice With the impact of European power and a new era of enforced international trade in the 19th century arising from globalisation, Chinese medicine became a major trade sector.

Embracing international standards of modernity, many educated and influential young Chinese chose to study biomedicine (the application of biological knowledge to human health), particularly in Japan. At the end of the century, practitioners of Chinese medicine became the target of repressive measures to marginalize "superstitious" and "backward" practice. The traditional medical practitioners saw a necessity to appropriate standards common to biomedical knowledge, technology, education, and research. This meant standardized drugs doses,

5http://www.un.org/esa/population/publications/wpp2006/WPP2006_H ighlights_rev.pdf 
re-modification and re-packaging, attempts to evaluate traditional techniques through clinical trials, and reformulating acupuncture channels according to modern anatomical knowledge [3].

In China today, a synthesis of biomedical and traditional theory and practice can be found at many different levels. All medical practitioners have some training in both (indigenous and western) styles and this is reflected institutionally in the delivery of health care at hospitals, in varying degrees of integration of diagnosis, explanatory models of disease, therapeutic paths, and drug preparations. Pharmacology, acupuncture, massage, and the practice of "qi" techniques, are all part of the heath care service in the country. Chinese medicine has not been completely subsumed under the high tide of a globally powerful biomedicine. On the contrary, the transfer of knowledge and techniques is two-way, as is evidenced by the hugely important international trade in prepared Chinese medicines [3]. With mass emigration and the globalization of a plurality of medical traditions, Chinese medicine now exists in many different forms, transforming as it comes into contact with different cultures around the world. Examples of Chinese herbal products found in Nigeria (and elsewhere all over the world) include various brands of slimming tea, herbal tea, green tea, toothpaste, balms and ointments. These products are reported to have high nutritional values and user-friendly attributes, with most of them approved by the National Agency for Foods and Drugs Administration and Control (NAFDAC).

\subsection{Institutionalization of Local Technology Development in India}

The Indian environment is replete with certain plants of economic value. Some of these plants grow only in India, especially the north-eastern part. For a long time, the aboriginal peoples of that region have applied these plants for dietary, medicinal and other purposes [3]. About 5 decades ago, the Indian government identified the economic potentials of many of the plants and the knowledge of the people, and started to build formal institutions around them. One such institution is the North East Institute of Science and Technology (NEIST), Jorhat established in 1961 under the chemical science group of the Council of Scientific and Industrial Research (CSIR).

The original aim of NEIST was to develop indigenous technologies by utilising the immense natural resources of north-eastern India like Tea, Aromatic and Medicinal plants. Today, NEIST has about 300 staff and one branch laboratory together with two field stations in other suburbs of India [3]. Presently, NEIST is a full-fledged multidisciplinary research institution having several research areas like Medicinal Chemistry, Natural Products Chemistry, Synthetic Organic Chemistry, Biotechnology, Medicinal, Aromatic and Economic plants, among others. Over the years, the laboratory has produced more than 100 technologies in the areas of Agro-technology, Biological and Oil Field Chemicals. In the last couple of decades, the institute has also produced more than 150 $\mathrm{PhDs}$ to cater for the skilled human resource needed in its host region [23].

The achievements that followed the institutionalisation of IK and I-Tech development and transfer are significant. Box 1 gives details of one of such; and other ones by NEIST are as follows:

1) Development of know-how for “Arteether”, a potent new generation anti-malarial drug active against Chloroquin resistant malaria strains. The know-how has been transferred to M/s FDC Ltd., a Mumbai-based pharmaceutical company, for commercial production.

2) Development of agro-technologies for important medicinal and aromatic plants. The laboratory's contribution to extensive cultivation of citronella grass and extraction of oil has led to the establishment of a major citronella based agro-industry in the North-eastern region.

The role of traditional knowledge in economic transformation is emerging as an important foundation for community development. For example, in 2000 the Indian Department of Science and Technology helped establish the National Innovation Foundation, which focuses on scouting, spawning, sustaining, and scaling up grassroots innovations of relevance to sustainable development. The foundation's work builds on long-standing efforts by the Honey Bee Network and the Society for Research and Initiatives for Sustainable Technologies and Institutions to document local innovations. They have more than 10,000 documented innovations [1]. The National Innovation Foundation began its first national campaign in 2000 to scout innovations and outstanding traditional knowledge. It has since completed four national campaigns. By 2003 the foundation had documented more than 37,000 innovations in 350 districts of India. In addition, the National Innovation Foundation has access to another 6000 traditional knowledge examples in the Honey Bee database managed by the Society for Research and Initiatives for Sustainable Technologies and Institutions. The main challenge facing the initiative is how to transform the innovations into products for wider commercial application. To make this possible the National Innovation Foundation is helping to obtain intellectual property protection for qualifying ideas. By 2004 more than 70 patent, trademark, and industrial design applications had been filed in India and abroad (Source: www.nifindia.org)

"Adapted from [1]

Box 1. Building on local knowledge-A success story from India*. 
The current production of citronella is about 500 tonnes and this has generated employment for about 22,000 persons in the rural sector.

3) Development and introduction of Agro-technologies for mushroom cultivation and popularisation of several protein-rich edible mushroom varieties in different areas of North-East India.

4) Process development for pesticides (viz. Phosphamidon, Quinalphos and Chlorfenvinphos), isolation and characterisation of compounds of plant origin having insecticidal and antifeedant properties.

5) Development of a new process for utilization of Banana plants for production of fibbers useful for making twines and fabrics in the conventional jute processing machines and also for making eco-friendly products like Carpets, Doormats, Bags, Flower vase, Table mats, Purse, Flower basket, Wall hangings, Shopping bags, etc.

\section{Methodology}

Information was collected from practitioners using structured questionnaires, focused group discussions and interviews. In all, 634 questionnaires were administered (230 in the aluminium casting cluster in Southwestern Nigeria, 104 in the bronze casting cluster in the Southsouth and 300 in the leather tanning cluster in Norther Nigeria). Of these, 599 were retrieved and analysed (213 in the aluminium casting cluster, 104 in the bronze casting cluster and 282 in the leather tanning cluster).

\section{Indigenous Technologies in Nigeria: Major Characteristics, Skills Acquisition Methodology and Innovation Potentials}

Nigeria is greatly blessed with gifted hands that are laboriously engaged in various types of indigenous technologies. There is hardly any part of the country that does not have a remarkable indigenous technology to show for its existence. The indigenous industries among others include the production of pots from clay and aluminium metal scraps, textile making, cloth weaving, bronze casting, leather tanning, and the like, in various parts of the country. The indigenous knowledge supporting these industries is generally passed on from generation to generation and hence it is a tradition in specific locations to produce specific products. The method of IK transmission and skills acquisition is largely through observation and apprenticeship [15].

Our focus in this section is to discuss some of the indigenous technologies dominant in various parts of Nigeria, based on our research findings. The discussion focuses on aluminium pottery in the South-West (notably Saki in Oyo State), bronze casting in the South-South (notably Benin in Edo State) and leather tanning in the Northern parts of the country (notably Sokoto, Zamfara,
Kano, Jigawa, Bauchi and Borno States). Specifically, we briefly describe the characteristics of these technologies and the practitioners, technological learning in the clusters and potentials for innovation as illustrated in the success story from India (Box 1).

\subsection{Aluminium Casting in Saki (South-Western Nigeria)}

Aluminium casting is a well established trade in the South-Western part of Nigeria. It is predominant in Oyo and Osun States. As gathered in the Saki cluster (Oyo State), the first set of practitioners introduced the trade in Saki when they returned from Ghana on repatriation in 1969. Faced with unemployment and the attendant welfare problems, the returnees decided to carry on with the practice of aluminium pot casting, the technique and methodology they were exposed to in Ghana. The practice, within a short time, became so embraced in the Saki zone that the home based people became interested and enrolled as apprentices. Most of the initial apprentices had no formal education. Later, primary school leavers, either because of interest in the practice or lack of funds for further education started to show interest and enrolled as apprentices. It was gathered that the practice did spread from Saki to other parts of the South-West. The Saki origin of the practice was confirmed by the fact that most indigenous aluminium pots sold in Nigeria today are trade-marked with the word "Saki" inscribed on them, regardless of where in the region they were produced.

The major raw material for indigenous aluminium casting is processed aluminium metal obtained in form of scraps from household utensils and other disused aluminium products. These scraps are melted in earthen furnaces and locally fabricated crucibles using firewood or palm kernel shells for fuel. Molten aluminium is poured into mud or clay moulds to form desired products. These products comprise cooking pots of various sizes. Over the years, the casting practice has evolved to the point customised products for groups and individuals now emanate from the cluster. These generally include pots with capacities and shapes specified by customers. In that manner, customers have been a major source of innovation in the aluminium pottery cluster [15]. However, apparently due to the imperfections associated with the raw material or the production process, finished products are sometimes unsatisfactory—either leaking or too weak to withstand prolonged usage [15].

\subsubsection{Sources and Characteristics of Practitioners}

Almost $90 \%$ of the practitioners were introduced to the practice as an apprentice. Very few learned the professsion as a member of a practicing family. Very negligible number of people learned the job through an institution or 
as an observer of the practice. In most of the cases, aluminium foundry is not a family tradition. Almost all the practitioners (94\%) got engaged in the profession out of sheer interest and only few of them were forced into the practice by their parents.

\subsubsection{Learning and Capability Acquisition}

Nearly all the practitioners (99\%) acquired their knowledge informally, that is, without proper documentation but through oral instructions, observations and learning by doing. Only a few of them (1\%) acquired this knowledge through a formal learning. They claimed that if an apprentice could focus very well on the job, within a short period, say, 2 - 3 years such could be trusted with casting work and would be able to deliver good product. Some apprentices with good focus acquired the skill within one year of apprenticeship, but masters often hold on to them for as long as three years which in most of the cases is the agreed time of learning. There is a hidden advantage here for the masters; the apprentices provide free labour to the masters all through their period of apprenticeship.

Observations on the field revealed that the trade is practiced in groups, thus, learning-by-doing is enhanced. Casting is not easily done by one individual performing all aspects of the work. Many people get together in the foundry and do several distinct works towards producing finished aluminium products. Where a single individual handles every aspect of the casting work, the process becomes very slow and the number of products produced per day or week is greatly reduced compared to a situation where practitioners are organized into teams. Figure $\mathbf{1}$ shows few of the practitioners as they engage in casting of molten aluminium and Figure 2 shows some finished pottery products.

Majority of the practitioners agreed that it will take at least an average of 3 years to learn the profession without documentation. 92\% of those interviewed believed that anybody who is interested can learn the trade, 6\% believed that people with some special abilities (presumebly those with skills in arts and crafts) are better candidates to learn the trade while a small percentage of them (1\%) opined that people of specific extraction are those who can learn the trade effectively. It is obvious here that the trade is open to parties who are interested and that participation does not require strict or special abilities to learn. It is to be noted that the ease of learning is conditioned by the knowledge form. If the knowledge surrounding the trade remains largely tacit, it will be unnecessarily difficult to acquire and master.

It was observed that a large proportion of the practitioners are not well educated. The capability to cast advanced products (such as engine blocks, cylinder heads, hosing and other similar enclosures) which their method

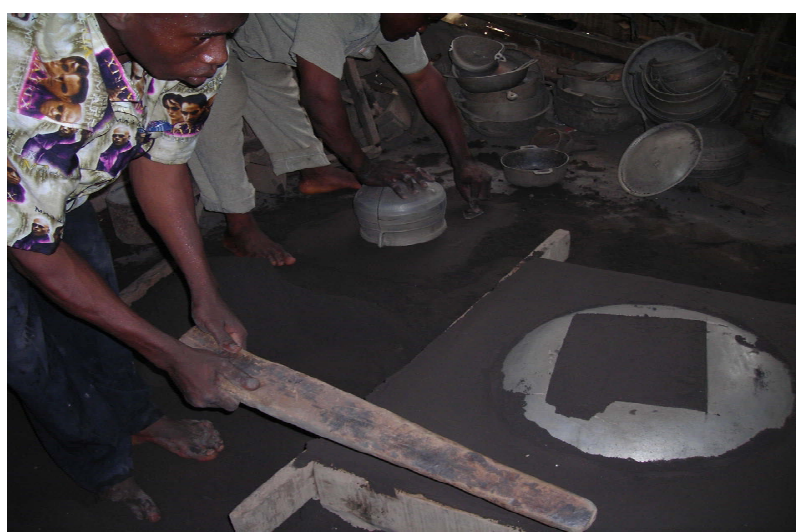

Figure 1. The process of sand casting.

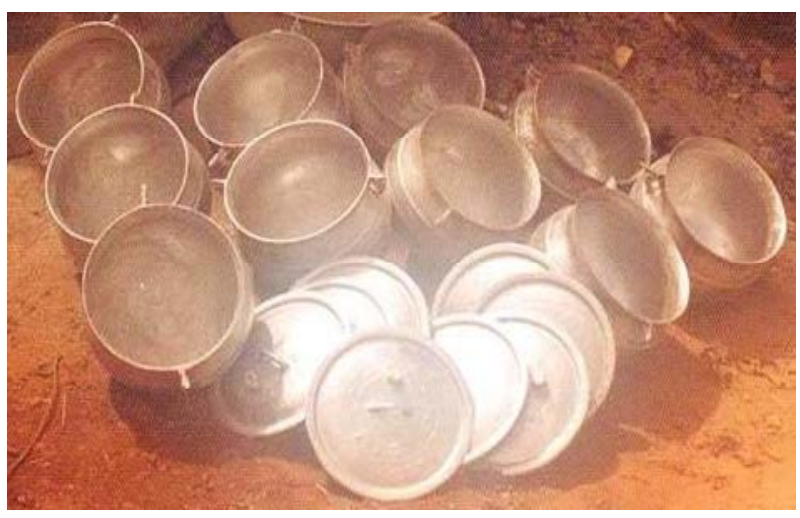

Figure 2. Finished aluminium pots.

of production can really produce has not been harnessed. Coupled with the foregoing, there was no evidence of interactions with tertiary institutions or knowledge centres that can help in improving skills as well as product and process development. This is in spite of the fact that one of the campuses of a frontline polytechnic (with various engineering courses) is situated within the same locality as the pottery cluster.

\subsubsection{Innovation/Upgrading Challenges and Potentials}

Though the existing practitioners, majority of which are male (95.5\%), would largely like to continue with the trade, there is a general concern about the future of the trade as new apprentices are now hard to find. In fact easy access to motor cycles and tri-cycles as commercial means of transportation was said to have further accentuated the problem of apprentice scarcity. This is because young persons who otherwise would consider apprenticeship as an option now prefer the apparently easier money-making ventures like commercial motorcycle riding.

On the possibility of widening the practice through training of people who are interested in the trade, 95\% of the practitioners agreed to train others using informal 
methods that were employed to train them. They, however, would like that schools are set up to train apprentices and if given the opportunity, they would like to instruct in such a school. Indeed, almost all the practitioners agreed to upgrade their skills if given the opportunity. They were also of the view that small training groups could be set up in different localities, if the setting up of schools will take a long time to be realized. They indicated willingness to instruct in these small training groups. The few among the practitioners who expressed reluctance to train others gave reasons such as not having enough time for the training because they are interested in furthering their education, while still in practice.

About one tenth of the practitioners were found to have, at one time or the other, abandoned the profession for between 2 to 5 years at a stretch. The reasons usually adduced for the break include low demand, health-related problems (these may be due to stress from the work) and inadequate finance. The break is understandable because the trade is open to competition from other producers scattered all over the South-West. Moreover, ready substitutes can be found for certain product ranges including the small household pots and spoons. Improving capabilities to the extent that products apart from pots and spoons originate from the cluster would have added more economic value to the profession and the locality. The seemingly preferential focus on the relatively simple pots and spoons is, however, not pre-conditioned by low capabilities alone. There is a general preference for aluminium pots and spoons within the Nigerian social context, especially in the South-West where large-scale cooking for social activities like wedding ceremonies or other big social events is common. In fact, every household is desirous of having sets of aluminium pots. A competitive edge over industrial aluminium products exists in this regard.

Certain specific opportunities for the growth of the trade were identified by the practitioners. These include improved methods of production (for instance, introducetion of automation in the production process), increasing demand, good export potential, adequate water supply and absence of close substitutes for most products, as the top five opportunities for growth and profitability. as the top five opportunities for growth and profitability. Other aluminium products from the industrial sector are not regarded as ready and available substitutes to the indigenous products. One may infer from here One may infer from here that the practitioners have been able to define their markets and created a niche that the more refined industrial products cannot satisfy. Limited exportation of these products currently takes place especially to the West African coast.

The role that modern science and technology can play in the aluminium casting cluster is not to be overlooked in upgrading the cluster, more importantly as regard the automation of certain stages of the production process. Such efforts as that made by the National Agency for Science and Engineering Infrastructure (NASENI) in reverse-engineering a $100 \mathrm{~kg}$ rotary furnace is to be acknowledged and deployed within the cluster. The challenges associated with melting the metal would then be largely overcome. It is to be noted that NASENI is presently making efforts to produce similar furnaces with lower capacity and cheaper costs for immediate deployment in micro- and small-scale industries. Government's role within this context will involve the provision of funding and equipment as well as capacity building. This could be done through organised associations, co-operative societies or micro-finance banks. Support could also come from government in the form of providing organised sources of raw materials and greater access to markets, particularly outside Nigeria.

\subsection{Bronze Casting in Benin (South-South) Nigeria}

\subsubsection{Technology Characteristics}

The raw materials for bronze casting are largely metal scraps obtained both from within and outside the locality. The major equipment comprises pit furnaces and crucibles. Furnaces and clay crucibles are built by the practitioners themselves. In very few cases, low-tonnage graphite crucibles are imported. The production technique is the lost wax method. Although the practice is not seasonal, operational disturbances may be encountered during the rainy season if the sites of the furnaces are without sheds or roof. The most prominent bronze casting products, some of which are shown in Figure 3, are heads or bust of various objects. The prominence of these products is connected, to a certain extent, with the capabilities of the practitioners and the demands that have existed over the years. Depending on the sizes of the products, the time spent on the production varies.

\subsubsection{Sources and Characteristics of Practitioners}

Bronze casting in Benin is a male dominated trade like many other trades requiring working with very high temperature and high level of physical exertion. The survey showed that about $96.2 \%$ of practitioners were male while only $3.8 \%$ were females. Across the two sexes, about $60 \%$ of practitioners were between 20 to 35 years of age. About $13 \%$ were above 35 years, while $6 \%$ are below 20 years of age. In terms of literacy level of practitioners, about $71 \%$ of respondents were found to possess secondary education, technical/vocational education $2.9 \%$, and $13.4 \%$ were educated to tertiary level. $10.6 \%$ of practitioners had only primary education and only $1 \%$ had no formal education. This educational level is different 


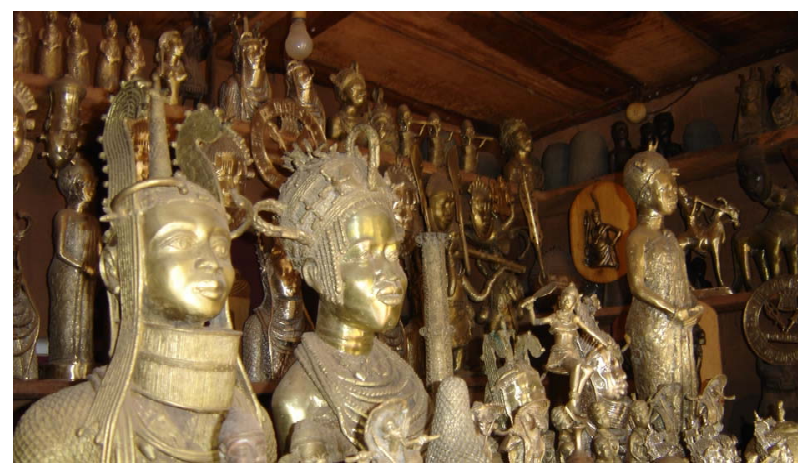

Figure 3. Benin bronze cast products.

from those in Saki and can contribute to the intricate designs.

It is important to note that less than $4 \%$ of practitioners were born outside the traditional Igun bronze casting lineage of Benin. This is conditioned by the existence of a restrictive requirement of naturalization into the bronze casting family by "outsiders" which makes the trade less attractive to non-Igun family members, who may not want to abrogate their own family identity. What this entails is that the naturalization requirement serves as entry barrier to preserve the economic appeal of the trade for the benefits of members of the traditional bronze casting family. Notwithstanding the observed entry barrier to the trade, bronze casting holds good potentials for employment generation especially among the youth in the area.

\subsubsection{Learning and Capability Acquisition}

Learning in the bronze casting cluster occurs mainly by doing, and knowledge is transferred through two major routes. The primary route of knowledge transfer is from the older generation to the younger within the Igun family. The secondary mode of knowledge transfer-though not prevalent-through which non-Iguns acquire capabilities is through apprenticeship. The strong appeal of the trade to the youth as revealed by the age distribution of practitioners suggests a competitive strength in favour of the trade. Practitioners being largely in their most productive years are likely to bring this advantage to the trade in terms of creativity, youthful strength, and productivity. The high profit from the products is also an attraction. Though rooted deep in culture and tradition, the predominance of youth in the trade is likely to affect the nature and pace of contact with modern technology as youths are more likely to be receptive to new ideas and experimentation. However, this may not materialize due to lack of technical support, training/skill upgrading, exposure and involvement of business developers. The age distribution advantage when combined with increasing entry of practitioners with more than secondary level education will further boost the appeal of the trade to other youths and may help in future increase the international appeal of the trade.

\subsubsection{Innovation/Upgrading Challenges and Potentials}

The Bronze casting trade has been sustained over many centuries largely by being rooted strongly in the culture and tradition of the people. Nevertheless, it has wielded great economic potential to renew and sustain the interest of the present generation of practitioners. When asked about the major strengths of the trade, practitioners cited the top five strengths of the trade as its strong cultural root (88\%), good export potential (86\%), and increasing interest of the young to continue the trade $(63 \%)$, absence of close substitute competing with Benin bronze arts (53\%), and increasing local and international demand for products (48\%).

The greatest challenge facing the trade is lack of adequate finance. Most of the practitioners indicated that inadequate finance was the reason they could not purchase new equipment, improve their processes or export their products in spite of the international appeal that it has. Equally very important are the challenges of lack of technical and financial support from government (98\%) for the development of the technology, inadequate water supply (98\%), erratic power supply (97\%) and shortage of high quality materials (32\%). According to some practitioners interviewed, some foreigners have shown interest in the products with the intent of promotion for global market exploitation.

Enhancing the competitive value of this I-Tech cluster rests on two distinct needs. In the first instance, there is an urgent need to preserve the integrity of the knowledge surrounding the technology by ensuring that the knowledge is codified. At present, despite the high level of artistic and tourism attention that the cluster has generated, not much has been done to systematically transform the underlying knowledge from its largely oral form to codified or documented forms. Besides the preservation of knowledge, such efforts would remove entry barriers and encourage increased participation in the trade. Knowledge centres, government and the private sector have significant roles to play along these lines. Secondly, the deployment of modern science and technology (S\&T) is required. As with the Saki cluster, the National Agency for Science and Engineering Infrastructure (NASENI's) rotary furnaces would also find applications here as much as the need for an organised source of raw materials. The need for government to show commitment through the provision of adequate infrastructure in terms of modern equipment, energy, adequate transportation, funding and access to market goes without saying. Again, these would be greatly facilitated in the presence of organised associations, co-operatives or training schools. 


\subsection{Leather Tanning in Northern Nigeria}

\subsubsection{Technology Characteristics}

Leather tanning is generally predominant in Northern Nigeria. The areas covered by our research are shown in Figure 4. The term tanning refers to a series of processes in which raw skins and hides are converted into more durable and benign leather products. These processes are aimed at making the skin or hide durable by making it non-putrefactive and equally yielding a product with technical characteristics suitable for a wide range of purposes. Tanning simply means treating skins and hides with certain chemical reagents called tanning agents in order to produce leather of high quality. Leather is created through the tanning of hides and skins of animals, primarily cattle hide. The process of tanning converts the putrescent skin into a durable, long-lasting and versatile natural material for various uses [16]. The leather and fur industries are differentiated by the importance of their raw materials relative to the source-animals. In the leather industry, the raw materials are a by-product of the meat industry, with the meat having higher value than the skin [15]. The fur industry uses raw materials that are higher in value than the meat and hence the meat is classified as a by-product.

Indigenous Leather Tanning in Northern Nigeria (Figure 5) is popularly referred to as "Jima". It is done by

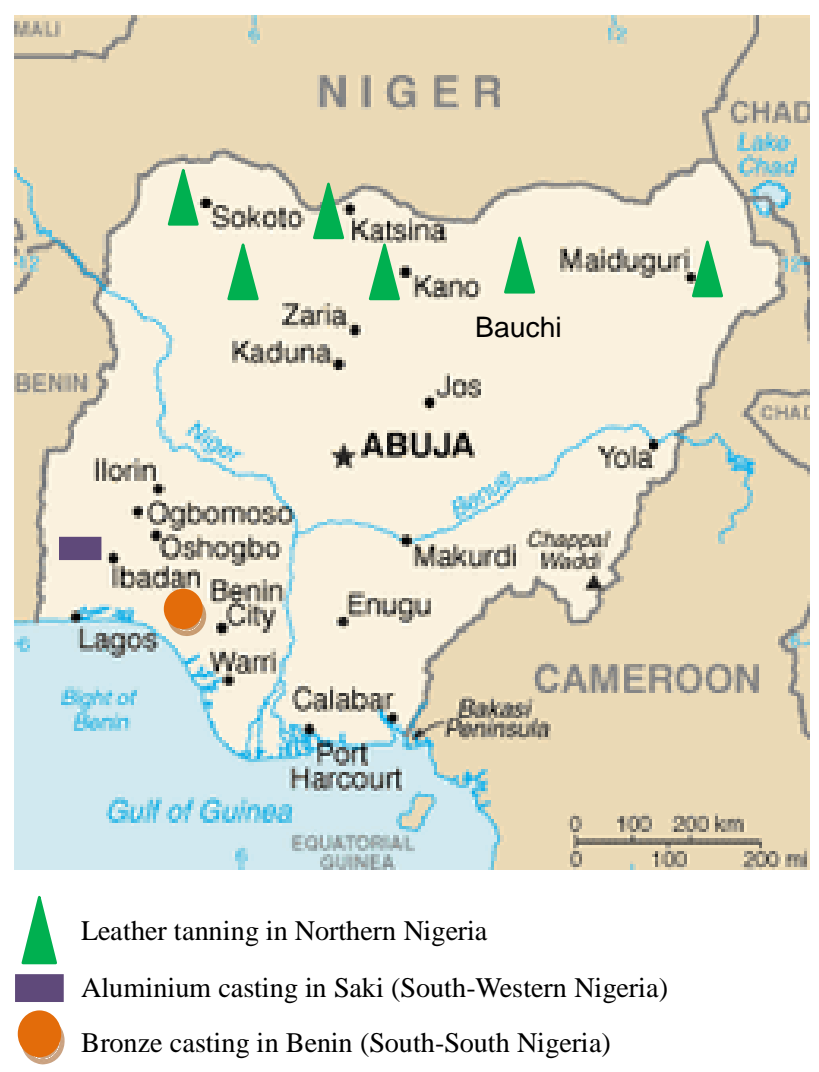

Figure 4. Map of Nigeria showing the study areas. vegetable tanning involving the use of "Bagaruwa" pods (Acacia nilotica). This is a popular plant among local tanners in Northern Nigeria. It is reported that the plant had been used in Egypt as a tanning agent between 2000-1570 BC. [16]. The plant is endowed with properties which have good coloration and rapid penetration on skin. It also softens leather very quickly and with ease. The only product of the indigenous leather tanning trade is processed leather from the skin of various animals such as goat, sheep, cow, tiger, snake, crocodile, lizard and other animals. When asked to rank in order of importance the skins most processed based on availability, ease of processing and marketability the ranking in Figure 6 emerged, with Tiger, Lizard and Crocodile skins being the least produced.

\subsubsection{Sources and Characteristics of Practitioners}

About $86 \%$ of respondents claimed that leather tanning is a family tradition. Thus their involvement in the trade has its root in the knowledge of the trade being well established in the family for many generations. Others held that their involvement in the trade is based on personal interest, independent of family attachment. Respondents

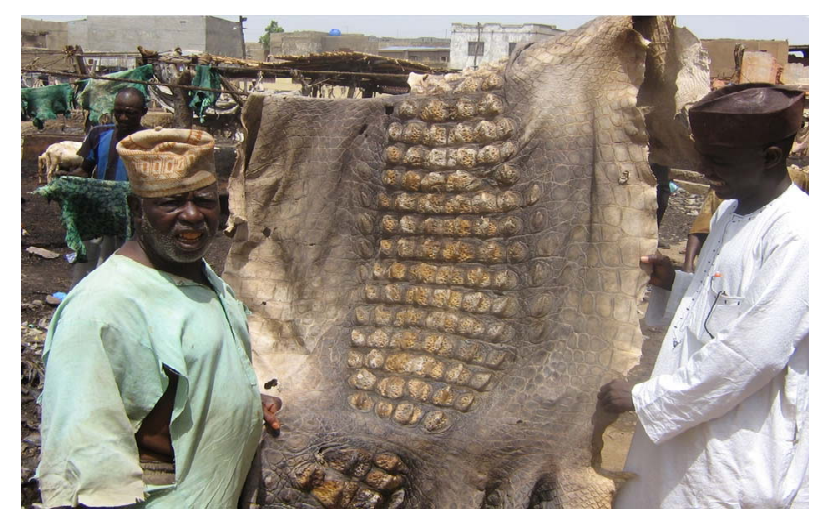

Figure 5. Tanned leather in Kano.

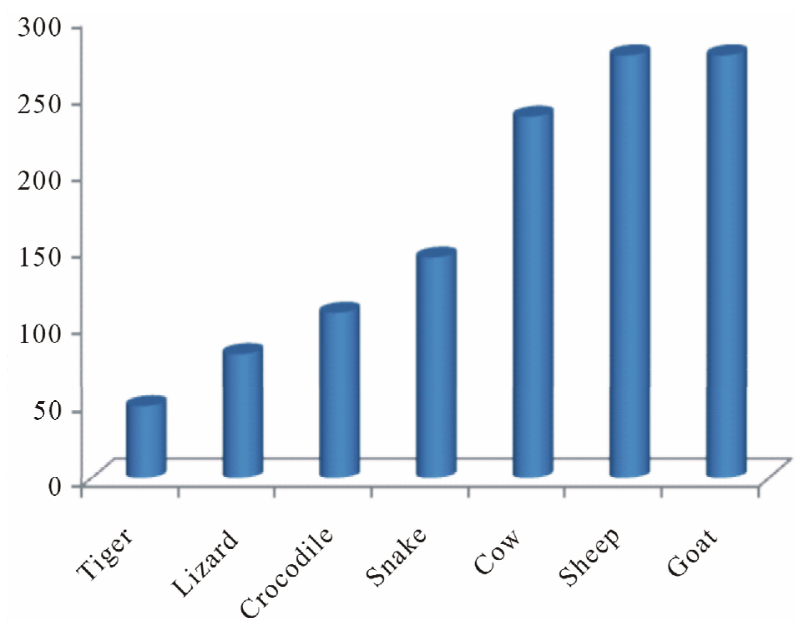

Figure 6. Animal skins most processed. 
overwhelmingly agreed that any interested person could learn the trade. Close to $90 \%$ of practitioners claimed that they willingly chose the trade and were not forced into it as a result of family attachment or any other factor.

\subsubsection{Learning and Capability Acquisition}

The mode of knowledge transmission in leather tanning is informal as learners take oral instruction; and capability is acquired through practice. About $97 \%$ of practitioners learnt the trade this way. Because a large percentage of apprentices have leather tanning as a tradition in their family, they start learning as help hands, taking instructions, observing and learning to perform increasingly difficult tasks in the process. Apprentices that learn as members of practicing families generally spend less time in apprenticeship. About $76 \%$ of those who responded to the enquiry on length of apprenticeship (51\% of total respondents) claimed they acquired the knowledge in less than three years. Only $3 \%$ claimed that written materials formed part of their training. Meanwhile the assertion could not be verified as the materials were not available as at the time of the survey.

Contrary to what was observed in the indigenous aluminium and bronze casting clusters, the knowledge system around leather tanning has evolved to become much more systematic, with advanced supporting technologies. Specifically, there are two federal research institutes supporting leather technology education and practice in Nigeria. While the National Research Institute for Chemical Technology (NARICT) carries out advanced research in chemicals and leather, the Federal College of Chemical and Leather Technology (CHELTECH) Nigeria provides courses of instructions, training and research in chemical, leather and leather products technology. Due to the activities of these institutions, the IK of leather tanning is now largely codified and S\&T applications in the industry are relatively been appreciated for further promotion by domestic firms.

\subsubsection{Innovation/Upgrading Challenges and Potentials}

In spite of the apparent successes, a number of specific challenges were identified that hinder the growth of the cluster. First, inadequate participation of formal institutions and training/skill upgrading of the local leather tanning practitioners. Secondly, although the two formal institutions identified earlier are located within the leather tanning cluster, there is no appreciable engagements between graduates of these institutions and the local practitioners. Graduates of the formal sector are largely employed in factories and rarely practice as entrepreneurs among the local leather tanning population. Thus, the influence of the activities of these institutions, especially on the knowledge transmission and apprenticeship sys- tems—on the local practice is still largely limited. Hence, the challenge is not the location of the institutions but the lack of integration.

\section{Upgrading, New Frontiers and Opportunities for SMEs: Policy Issues and Strategies for Action}

There are reasonable arguments in favour of a position to upgrade and advance for new frontiers for the IK studied in this paper. For instance, the world footwear and leather products sector can easily be fed from these IK and thereby presents opportunity for SMEs. Although many developing countries, Nigeria inclusive, possess strong potentials with respect to raw material and human resources, they have mainly remained suppliers of raw and semi-finished products [24]. This has been attributed to a limited number of African companies and local industries having developed the capacity to produce finished products. This implies that if efforts are geared at solving this problem, Nigeria will favourably compete with some other major exporters of leather and other I-Tech products. It was suggested that efforts towards achieving this feat will provide partly a solution to the call for the diversification of Nigeria's non-oil sector and consequently increase the country's revenue generating capacity thereby reducing unemployment [24].

From the three country cases discussed earlier, three significant lessons are identified:

1) The role of government as the provider of the initial impetus in the deployment of IK and I-Techs for national innovativeness and development cannot be substituted. While mechanisms may vary by country, it is important to note that government has to demonstrate sufficient commitment and will power for any meaningful achievement to occur by putting in place adequate mechanism in the form of policy and conducive environment to drive the development of these IK and I-Techs. In India, for instance, government created strong institutions to harness the power of IK and I-Techs while opening up new frontiers for their application. On the other hand, policy and regulatory mechanisms created the necessary pull.

2) I-Tech practitioners were open to knowledge, particularly as is available in knowledge centres. As was demonstrated in China, achieving a convergence between state-of-the-art in modern scientific and technological knowledge and the traditional knowledge and practices will go a long way in enhancing the impact of IK and I-Techs.

3) The role of institutions is critical. Strong research, development and brokerage institutions are required to move the IK and I-Tech sector forward on the learning curve, assist in the codification of knowledge and facilitate product development and standardisation. The role 
played by the National Innovation Foundation in India is of note in this regard. This is basically because they support grassroot innovation and move them to the next level by scouting and documentation of the IKs and innovations; conduct of value addition $\mathrm{R} \& \mathrm{D}$; engagement in business development around the IKs; Intellectual property protection; dissemination and diffusion of innovations around the IK and I-Techs [25].

Aside these lessons from the country case, it is worthy of note that technology business incubators (TBIs) are important especially for business development. Research [26] had shown that Technology Incubation works in achieving the goals of technology commercialisation by facilitating the growth of technology-based entrepreneurrial firms. Some scholars [26,27] developed a theory about the characteristics of a region that will increase the likelihood of successful incubation of start-up technology firms. The necessary regional characteristics for successful incubation include the presence of one or more technology generators and a sufficient skilled labour force that can provide potential clients with employees who have the critical skills to fill the newly created technology-oriented jobs. Given that these are generally available in the relevant I-Tech cluster locations, the success potentials of incubators within the regions are high.

\section{Recommendations}

1) There is the need for government, particularly at the grassroots, to acknowledge and support I-Tech development. Several ways by which this could be done includes the facilitation of capacity development; creation of specialised markets which would serve as product outlets and possibly evolve to secure international interest ${ }^{6}$; the recognition of outstanding individuals; and the provision of venture funding.

2) Institutions are identified as critical; thus the existing ones, especially research institutes, need to be funded and equipped to conduct value added R\&D for the development of the I-Techs. The activities of existing institutions like NASENI, NARICT and CHELTECH are acknowledged; however, they need to broaden their horizon and focus on the development of the country's IK and I-Techs.

3) The potentials of TBIs to spur economic growth would be significantly undermined in relatively rural regions, where investment capital is scarcer and the regions lack the forward and backward economic linkages of larger metropolitan regions [28]. Thus, government at all levels as well as entrepreneurs need to demonstrate much greater commitment than is required for TBIs in

\footnotetext{
${ }^{6}$ The amount of international interest secured by the Osun River and the annual Osun Osogbo celebrations in Osun State suggests that the proposition made here is a possibility. The Osun shrine has already been designated a Cultural Heritage site by UNESCO.
}

city centres.

4) In the area of capacity building, existing tertiary institutions and research institutes located around IK and I-Tech clusters could play the role of creating specific training programmes for the I-Tech practitioners to facilitate knowledge transmission. The institutions could also assist in upgrading and formalising the current apprenticeship system of capacity building.

5) Knowledge centres, especially tertiary educational institutions located around identified IK and I-Tech clusters have a significant role to play. Researchers from such institutions could be involved in mapping the IK system, and help in the codification of knowledge, standardizing procedures, improving processes and facilitating knowledge transfer. Students of such institutions, particularly those undertaking related studies (and undergraduate or postgraduate research) could be made to work with IK and I-Tech practitioners for stipulated periods. Besides the benefit of knowledge transfer, such arrangements would encourage practitioners to embrace formal knowledge and improve their skills levels.

\section{Concluding Remarks}

In Nigeria, the leather tanning, aluminium and bronze casting indigenous industries creates employment opportunities, promote effective resource utilization and thereby contributes to the process of industrialization and national development [25]. These IK and I-Techs presents particular opportunities for SME exploitation and development. They can be leveraged upon to provide comparative advantage for the country as is the case with herbal medicine in India and China. This can be achieved through institutional and policy frameworks which include systematic documentation, involvement of research institutions in value addition $\mathrm{R} \& \mathrm{D}$, provision of adequate funding mechanism for exploitation particularly in business development around the IKs; Intellectual property protection, upgrading, engagement in dissemination and diffusion of innovations around the IK and I-Techs.

\section{Acknowledgements}

The authors gratefully acknowledge the support and contributions of the other members of NACETEM's indigenous knowledge research team that originally implemented the projects Indigenous Technology Mapping and Analysis of Skills Acquisition Methodologies in Nigeria. We thank specially Dr. O. A. Adetunji of the Materials Science and Engineering Department, Obafemi Awolowo University, Ile-Ife as well as Drs. A. Y. Fasasi and A. D. Pelemo of the Centre for Energy Research and Development, Obafemi Awolowo University, Ile-Ife who were all involved in the study of the Aluminium and Bronze Casting Industry. The studies were carried out with fund- 
ing from the Federal Government through the Federal Ministry of Science and Technology. Prof. Turner T. Isoun, the Honourable Minister of S\&T at that time is gratefully acknowledged.

\section{REFERENCES}

[1] A. Adetola, J. Goulding and C. Liyanage, "Collaborative Engagement Approaches for Delivering Sustainable Infrastructure Projects in the AEC Sector: A Review," International Journal of Construction Supply Chain Management, Vol. 1 No. 1, 2011, pp. 1-24.

[2] UN Millennium Project, "Innovation: Applying Knowledge in Development," Task Force on Science, Technology and Innovation, Earthscan, Vancouver, 2005

[3] D. Acharya and A. Shrivastava, "Indigenous Herbal Medicines: Tribal Formulations and Traditional Herbal Practices,” Aavishkar Publishers and Distributor, Jaipur, 2008.

[4] C. C. Gakuru, "Remodelling Traditional and Indigenous Knowledge,” 2006. http://knowledge.cta.int/en/content/view/full/3006

[5] A. A. Egbetokun and W. O. Siyanbola, "Reliance on Natural Resources Is Africa’s Undoing,” 2008. http://www.africanexecutive.com/modules/magazine/artic les.php?article $=3030$

[6] A. A. Egbetokun and W. O. Siyanbola, "Linking Science, Technology and Innovation (STI) For Development,” 2008. http://www.africanexecutive.com/modules/magazine/artic les.php?article $=3043$

[7] A. A. Egbetokun and W. O. Siyanbola, "Making Science, Technology and Innovation Relevant,” 2008. http://www.africanexecutive.com/modules/magazine/artic les.php?article=3069

[8] D. M. Warren, L. J. Slikkerveer and D. Brokensha, “The Cultural Dimensions of Development: Indigenous Knowledge Systems,” Intermediate Technology Publications, London, 1995.

[9] L. Grenier, "Working with Indigenous Knowledge-A Guide for Researchers,” IDRC, Ottawa, 1998.

[10] Nemingha on Hubpages, "Mummification: All about Egyptian Mummies 79,” 2012. http://nemingha.hubpages.com/hub/Mummification-All-A bout-Egyptian-Mummies

[11] A. Afuah, "Innovation Management," Oxford University Press, New York, 2003, pp. 1-390.

[12] http://www.csir.res.in/External/Heads/aboutcsir/lab_phon e/rrl-jorhat.htm

[13] S. Lall, "Human Resources, Technology and Industrial Development in Sub-Saharan Africa,” In: A. Chhiber and F. Stanely, Eds., Economic Reform in Sub-Saharan Africa, World Bank, Washington DC, 1991.

[14] United Nations Conference on Trade and Development (UNCTAD), “The Least Developed Countries Report 2007: Knowledge, Technological Learning and Innovation for Development," United Nations Conference on Trade and Development, Geneva and New York, 2007
[15] National Centre for Technology Management (NACETEM), "Indigenous Technology Mapping and Analysis of Skills Acquisition Methodologies in the Aluminium and Bronze Casting Industry in Nigeria,” Policy Research Project Funded by the Federal Government of Nigeria, 2008.

[16] National Centre for Technology Management (NACETEM), "Indigenous Technology Mapping and Analysis of Skills Acquisition Methodologies in Nigeria: Leather Tanning,” Policy Research Project Funded by the Federal Government of Nigeria, 2008.

[17] H. O. Aderemi, "Women in Technological and Non-Technological Enterprises: Divergent or Convergent Paths?” LAP LAMBERT Academic Publishing AG \& Co. KG, 2010, pp. 1-133.

[18] V. Ramachandran, "An Assessment of the Private Sector in Nigeria,” 2006. http://www1.worldbank.org/documents/ICA005.pdf

[19] I. O. Oyefuga, W. O. Siyanbola, O. O. Afolabi, A. D. Dada and A. A. Egbetokun, "SMEs Funding: An Assessment of an Intervention Scheme in Nigeria," World Review of Entrepreneurship, Management and Sustainable Development, Vol. 4, No. 2/3, 2008, pp. 233-245. doi:10.1504/WREMSD.2008.018227

[20] C. Carpenter, “SME Finance in Nigeria,” 2006. http://www.ypforum.org

[21] UNDP/SMEDAN Draft National Policy on MSMEs Abuja, 2007, pp. 1-83.

[22] A. Olayinka "The Role of SME's in Poverty Alleviation in Nigeria,” Journal of Land Use and Development Studies, Vol. 3, No. 1, 2007, pp. 124-131.

[23] Regional Research Laboratory (RRL), "Jorhat News Council of Scientific \& Industrial Research,” 2009. http://www.csir.res.in http://jorhat.nic.in/rrl.htm http://www.geocities.com/rrljorhat2000/rrlaugust.html

[24] U. Amakom, "Export Constraints of the Kano Leather Industry: A Study of Industrial Clusters in Nigeria," Nnamdi Azikiwe University, Awka, 2006

[25] C. F. Essien, "Empowering Indigenous Industries for National Development,” JORIND, Vol. 9, No. 1, 2011, pp. 10-16.

[26] W. Charles, et al., "Technology Innovation Centres: A Guide to Principles and Best Practices,” Claggett Wolfe Associates, Auburn, 1999.

[27] W. Charles, P. Gottwals and M. Spoto, "Incubator Funding Guide: New Jersey Incubator Expansion Program July 2000,” Report Prepared for the New Jersey Commission of Science and Technology, Claggett Wolfe Associates, Trenton, 2000, pp. 1-42.

[28] A. Glasmeier, "The High-Tech Potential: Economic Development in Rural America,” Center for Urban Policy Research Campbell, New Brunswick, 1991. 